\title{
Criptococosis y embarazo $*$ Presentación de un caso
}

\author{
Dres. Guillermo Acosta Osio*, Juan José Acosta Osio**, Ana Falquez***, Juanita Escorcia****
}

La Criptococosis (Torulosis, Blastomicosis Europea), es una infección causada por una levadura conocida con el nombre de CRYPTOCOCCUS NEOFORMANS o Torula histolytica. A diferencia de los otros hongos sistémicos, el C. neoformans sólo se da en forma de un organismo esférico u ovalado único o en gemación y con un diámetro de 5 a 20 micras, el cual está rodeado de una amplia capa gelatinosa refringente que puede dividirse en 4 serotipos capsulares denominados A, B, C y D. Dicha cápsula es patognomónica de este organismo $(1,2)$.

El hongo crece en forma de colonias lisas y de color crema a marrón en medio de Sabouraud, a la temperatura ambiente y a $37^{\circ} \mathrm{C}$, los medios de cultivo con cicloheximida no son satisfactorios para este organismo ya que inhibe su proliferación. Su identificación se basa en el aspecto macroscópico y microscópico (se observan las típicas levaduras encapsuladas), en ciertas pruebas bioquímicas y su crecimiento a $37^{\circ} \mathrm{C} \mathrm{(2).} \mathrm{El} \mathrm{Cryptococcus} \mathrm{neoformans,} \mathrm{se} \mathrm{ha} \mathrm{ais-}$ lado a partir de los palomares, excrementos de paloma y del suelo $(2,3)$.

Por ser esta enfermedad no muy común y haberse presentado en una paciente con embarazo de término, decidimos presentar el caso por considerarlo interesante, además que son muy pocos los casos reportados en la literatura.

Historia clínica: Se trata de la paciente L.M.P.C., de 29 años G2, Pl, A0 con embarazo de 40 semanas (FUM: Dic. 17-1986. FPP: Sep. 24-87), casada y dedicada al hogar, quien ingresa al Hospital Universitario Metropolitano el 25 de septiembre de 1987 , remitida de centro hospitalario por presentar dislalia, hipertermia, anorexia desde hacía 10 días, por no responder a tratamiento con antibioticoterapia y analgésicos y para detectar cuadro cerebral.

La paciente ingresa en malas condiciones musculonutricionales, somnolienta, inquieta, lenguaje incoherente, las pupilas se encuentran isocoricas mormorrecreativas. Cuello sin masas, con dolor a la palpación y signos de Kerning y Brudsinski positivos. Pulmones normales, abdomen globoso por útero grávido, con fondo uterino de $30 \mathrm{cms}$, producto único, vivo, cefálico izquierdo y longitudinal, la FCF de 156 por minuto, dinámica uterina esporádica, el tono uterino normal.

\footnotetext{
* Profeser y Director Dpto. Ginecología y Obstetricia, Hospital Universitario Metropolitano.

** Médico Internista, Profesor Asistente de Medicina Interna, Universidad y Hospital Universitario Metropolitano.

*** Bacteriólogas y Docentes Laboratorio Clínico, Hospital Universitario Metropolitano.

* Aceptado para ser presentado en el XVIII Congreso Colombiano de Obstetricia y Ginecología.
}

Los genitales externos presentan condilomatosis en labio mayor, perineo y región anal, a la especuloscopia se encuentra abundante flujo blanco amarillento, fétido, no condilomas internos, el cervix sin erosiones, al tacto cervix cerrado sin dilatación, largo y formado, semiblando. Los reflejos osteotendinosos se encontraron aumentados, la paciente ingresó con diagnóstico de: 1) embarazo de 40 semanas, 2) meningitis bacteriana, 3) condilomatosis, 4) descartar septicemia.

Es hospitalizada para estudio de su cuadro neurológico y resolución de su condición obstétriça.

Se realiza el mismo día de ingreso punción lumbar el cual es reportado de aspecto turbio, glucosa $25.7 \%$, proteínas $130 \mathrm{mgs}$, células 780 por $\mathrm{mm}^{3}, 42 \%$ de PMN y 53 de MN. Hematíes escasos. El fresco reporta leucocitos 6-8 por campo, levaduras + , tinta china + y se observan levaduras compatibles con Cryptococcus neoformans. El VDRL reactivo 2 diluciones. La hemoglobina en 9 y el hematocrito en $28 \%$, los leucocitos en 15.700. En examen de orina se encontraron levaduras.

Todos los demás exámenes estaban normales.

En vista de los hallazgos clínicos y de laboratorio se decide en ronda realizar evacuación uterina con cesárea e inmediatamente iniciar tratamiento con Anfotericina B. La cesárea se realizó el mismo día obteniéndose producto masculino con $2.500 \mathrm{grs}, 48 \mathrm{cms}$ de talla, PC de $33 \mathrm{cms}$, PT: $29 \mathrm{cms}$ y PA $27 \mathrm{cms}$. El apgar fue de $8 / 10$ y 10/10.

$\mathrm{Al}$ día siguiente la paciente se encontraba obstétricamente bien, pero presentando deterioro progresivo de su estado general neurológico hasta el día 29 en que fallece. Los familiares no aceptaron autopsia y la placenta tampoco fue enviada a estudio histopatológico.

El cultivo de LCR reportó a las 48 horas crecimiento de Cryptococcus neoformans +++ . Fue negativo para bacterias. No se realizó HIV pues esta prueba sólo comenzó a realizarse en nuestro medio en diciembre de 1987.

Comentarios: La infección por C. neoformans se adquiere al inhalar el hongo, y la enfermedad puede afectar los pulmones, piel, huesos y articulaciones u otras partes del cuerpo con predilección por el sistema nervioso central. La infección pulmonar tiende a desaparecer espontáneamente, pero llega por vía hematógena hasta el cerebro formando conglomerados de criptococos en las áreas perivasculares de la materia gris cortical, ganglios basales y en otras áreas. Se dice que el $10 \%$ de los pacientes pueden tener lesiones cutáneas de las cuales se disemina el germen por vía hematógena (4).

Las meningitis por hongos son raras, la más común es la criptococosis; aproximadamente el $50 \%$ de los pacientes cursan con alguna entidad predisponente (neoplasias, admi- 
nistración de corticoesteroides o inmunosupresores, radioterapia, síndrome de inmunodeficiencia adquirida) (5).

Como datos clínicos tenemos que la mayoría de los pacientes cursan con meningoencefalitis al momento del diagnóstico y los síntomas tempranos son: cefalea, náuseas, marcha tambaleante, demencia, irritabilidad, confusión y visión borrosa, también se presenta rigidez de nuca y los signos de Kerning y Brudzinski positivos (6), como fue presentado por nuestra paciente. En 33\% de los pacientes se presenta papiledema, y un $25 \%$ parálisis de nervios craneales asimétrica, posteriormente se presenta coma profundo y compresión del tallo cerebral. Si existe enfermedad a nivel pulmonar, puede haber tos y dolor torácico, y en la radiografía de tórax existen infiltrados densos y circunscritos. La enfermedad puede dejar secuelas permanentes como demencia, cambios de la personalidad, hidrocefalia y ceguera (1).

Es importante hacer el diagnóstico diferencial de las lesiones en piel con la sífilis, con el impetigo rebelde y las pústulas acneiformes; las lesiones pulmonares se deben diferenciar de la tuberculosis $(6,7)$. La meningitis por criptococosis debe diferenciarse de la encefalitis bacteriana y de la demencia, entre otros (5).

El método más útil para el diagnóstico, a pesar de los estudios con que se cuenta actualmente (electroencefalografía, angiografía cerebral, escanografía cerebral), sigue siendo la punción lumbar. El frotis de líquido cefalorraquídeo centrifugado y tratado con tinta china, muestra las levaduras características en el $50 \%$ de los casos; además existe hipoglucorraquia, aumento de las proteínas y de 20 a 600 leucocitos por $\mathrm{mm}^{3}$ a expensas de los linfocitos. En el cultivo de líquido cefalorraquídeo se observan las colonias características. El $90 \%$ de los pacientes tienen antígeno capsular detectable en el líquido cefalorraquídeo o el suero, mediante aglutinación con látex $(1,4)$, que si comparamos, vemos que esta paciente tenía casi todos estos datos.
Silberfarb (8) realizó una presentación de criptococosis y embarrazo y además realizó una revisión de la literatura, encontrando en esa época que con el caso de él eran 10 los reportados en la literatura; la mortalidad encontrada fue del $50 \%$ y los cuadros clínicos con sus variaciones estaban entre lo ya comentado, pero estaba de acuerdo en que esta enfermedad asociada al embarazo es rara. Aitken y Symonds (9) fueron los primeros que examinaron la placenta, pero no encontraron evidencia de criptococosis; más recientemente Kida y colaboradores (10) reportaron criptococosis en la placenta de una paciente que además tenía síndrome de inmunodeficiencia y se encontraban como múltiples colonias encapsuladas en los espacios intervellosos. La paciente que falleció al segundo día de postparto tenía la infección a nivel pulmonar.

De todas formas estamos de acuerdo que esta entidad es rara durante el embarazo y que aunque existen ciertos factores predisponentes para esta enfermedad, se desconoce cómo el embarazo podría tener relación con la criptococosis.

Para el tratamiento se utiliza la Anfotericina B, sola o combinada con Flucitosina. La Anfotericina B se utiliza a dosis de 0.5 a $0.6 \mathrm{mg} / \mathrm{kg}$ por día si se utiliza sola, y si es combinada a dosis de $0.3 \mathrm{mg} / \mathrm{kg}$ por día; y la Flucitosina se administra a dosis de $150 \mathrm{mg} / \mathrm{kg}$ por día dividida en 4 dosis, cada 6 horas. Con cualquiera de los dos esquemas se ha encontrado curación en un 50 a $70 \%$ de los pacientes. El tratamiento se continúa durante 6 a 8 semanas y hasta que sean estériles 4 cultivos semanales de 2 a $4 \mathrm{cc}$ de líquido cefalorraquídeo. El uso de Anfotericina B por vía intratecal se reserva para los pacientes refractarios al tratamiento tradicional (1). Nuestra paciente aunque se le inició con Anfotericina no se obtuvo respuesta, por lo avanzado del cuadro; la Anfotericina puede usarse incluso antes de la resolución del embarazo, sin observarse alteraciones en el neonato (8).

\section{BIBLIOGRAFIA}

1. Bennett JE. Infecciones micóticas, Harrison: Principios de Medicina Interna, XI edición 1987; 146: 903-904.

2. Todd-Sanford: Diagnóstico clínico por el laboratorio. 6a. edición 1978; 20: 1170-1172.

3. Corrales SC, Ordóñez N, Londoño LM, Castañeda E. Determinación de anticuerpos contra Cryptococcus neoformans en un grupo de colombófilos. Biomédica 1987; 7: 100-4

4. Loaiza Loeza, M Salome. "Crytococcosis". Infectología. México 1978; 8(4): 387-395.

5. Betancourt S. Neurología, Fundamentos de Medicina 1978; 31: 303.
6. Medical Mycology. The pathogenic fungi and the pathogenic actinomycestes. 2a. edición, Editorial Jhon Willard Ripoon 1982; 582-85.

7. Nolting S, Fegeler K. Micología médica. Editorial Médica Bayer, 3a. ed., Alemania 1987; 98-101.

8. Silberfarb PM, Sarosi GA, Tøsh FE. Cryptococcosis and pregnancy. Am J Obstet Gynecol 1972; 112: 714-20.

9. Aitken y Symonds. Citado por Silberfarb (8 ídem).

10. Kida M, Abramowsky CR, Santoscoy C. Cryptococcosis of the placenta in a woman with acquired inmunodeficiency syndrome. Hum Pathol 1989; 20: 920-1. 